\title{
Perjanjian Hudaibiyah Sebagai Model Kepatuhan Terhadap Perjanjian Internasional dalam Perspektif Islam
}

\section{Sidiq Ahmadi}

Jurusan IImu Hubungan Internasional, Fakultas IImu Sosial dan IImu Politik, Universitas Muhammadiyah Yogyakarta Jl. Lingkar Selatan, Tamantirto, Yogyakarta 55183

sidiqahmadi77@gmail.com

Submitted: 2 August 2015, Accepted: 2 October 2015

\begin{abstract}
This research aims to explain why the Prophet Muhammad comply withThe Hudaybiya Treaty although in its articles are considered harmful. By answering the question above, it is expected to build a model of compliance to international agreement in the Islamic perspective. Christian ReusSmit'sintertistial conception of politics considered appropriate in this study because it provides space for the role of ideas such as identity and norm in explaining a political action. This study found Prophet Muhammad complieswith Treaty of Hudaibiyah because of political deliberation which integrate four type or reason: idiographic, purposive, ethical, and instrumental. Ideographic deliberation determines the formulation of interest (purposive deliberation). The formulation of these interests will determine the action (instrumental deliberation) in accordance with the available resources and external constrain faced, as well as appropriate with or not contrary to Islamic norms and universally applicable norms (ethical deliberation). Ideographically, based on identities: as believers who should obey Allah and His Messenger, as a noble people who hold the promise. Purposively, the mission of Muslims is to preach the religion of monotheism to all mankind, therefore the condition of peace and religious freedom must be realized. Ethically, the question of how should we act is answered by everything done must in concordance with Islamic rules and customary law norms which emphasize the obligation to comply with the concluded agreements. Instrumentally, the chosen action which in line with the formulated interest and in accordance with the norms of Islam is complieswith the peace treaty.

Keywords: Hudaibiyah Treaty, Compliance, International Agreements, Islam
\end{abstract}

\begin{abstract}
Abstrak
Penelitian ini bertujuan untuk menjelaskan mengapa Nabi Muhammad SAW tetap mematuhi Perjanjian Hudaibiyah walaupun dalam pasal-pasalnya dianggap merugikan. Dengan menjawab pertanyaan di atas diharapkan dapat terbangun sebuah model kepatuhan terhadap perjanjian internasional dalam perspektif Islam. Pendekatan konstruktivis dari Christian Reus Smit dianggap sesuai dalam penelitian ini karena memberikan ruang bagi peran dimensi ide seperti identitas dan norma dalam menjelaskan sebuah tindakan politik. Penelitian ini menemukan bahwa Nabi Muhammad saw tetap mematuhi perjanjianHudaibiyah karena pertimbangan politik idiografis, purposif, etis, dan instrumental. Pertimbangan ideografis menentukan perumusan kepentingan (pertimbangan purposif). Rumusan kepentingan tersebut akan menentukan tindakan (pertimbangan instrumental) yang sesuai dengan sumber daya yang dimiliki dan hambatan eksternal yang dihadapi, serta sesuai atau tidak bertentangan dengan norma Islam dan norma yang berlaku secara universal (pertimbangan etis). Secara ideografis didasari oleh identitas sebagai mukmin yang harus mentaati Allah dan Rasulnya, kaum yang mulia, sebagai kaum yang memegang janji. Secara purposif yang diinginkan oleh kaum muslim adalah mendakwahkan agama tauhid kepada seluruh manusia, oleh karena itu situasi damai dan kebebasan beragama harus terwujud. Secara etis, pertanyaan bagaimana kita seharusnya bertindak dijawab dengan harus sesuai dengan aturan Islam dan norma-norma bersama (customary law) yang berlaku yaitu keharusan mematuhi perjanjian. Secara Instrumental pilihan tindakan yang diperlukan untuk mencapai tujuan dan sesuai dengan norma islam adalah menaati perjanjian damai.

Kata kunci: Perjanjian Hudaibiyah, Kepatuhan, Perjanjian Internasional, Islam
\end{abstract}

\section{PENDAHULUAN}

Dalam buku Non-Western International Relations Theory: Perspective on and Beyond Asia, Acharya dan Buzan (2010) menyatakan bahwa selama ini teori HI masih sangat miskin terhadap perspektif non-Barat,

termasuk Islam. Padahal semakin banyak sarjana hubungan internasional yang mulai menggugat universalitas prinsip empirisme dan materialisme pendekatan teori hubungan internasional Barat. 
Diperlukan sebuah upaya mengkaji berbagai perspektif dari luar Barat agar dapat memahami fenomena internasional terutama di ruang yang berbeda misalnya di dunia Islam seperti di kawasan Timur Tengah. Acharya dan Buzan mempertanyakan jika terdapat ketidaksesuaian antara teori hubungan internasional Barat dan universalitas pengalaman manusia, tidak bisakah kita menggunakan pandangan dunia Islam (islamic worldview) sebagai basis generalisasi yang bisa menyediakan lensa alternatif dalam teorisasi (studi hubungan internasional)?

Walaupun masih banyak keterbatasan, menggunakan Islam sebagai sumber teorisasi dalam studi hubungan internasional sebagai sangatlah dimungkinkan. Salah satu yang ditawarkan oleh Tadjbakhsh sebagai sumber kerangka teoretik Islam dalam Hubungan Internasional adalah apa yang dipraktikkan oleh Nabi Muhammad saw:

"A primary foundation for the classical understanding of IR in Islam is basedon the original sources of the Qur'an, the Hadith (Sayings of the Prophet), theSunnah(the conduct of the Prophet) or ijtihad(interpretation), which couldcorrespond to what Acharya and Buzan call classical ideas, traditions andthinking contributing to "localistexceptionalism'” (Tadjbakhsh, 2010:176)

Sementara dalam hal sifat, Tadjbakhs (2010:185) menyatakan bahwa teori Islam tentang Hubungan Internasional adalah normatif.

"The nature of the Islamic theory on international relations is decisively normative, in the Aristotelian sense of sciences as not only a reflection on what is, but also on what should be/what must be done. It is based fundamentally not on empirical observations of behaviours between states and predictions of what behaviour would be, but on how institutions reflect the essence of an idea, a norm, a morality."

Oleh karenanya apa yang disimpulkan dari sumbersumber klasik teori Islam tentang Hubungan Internasional adalah merupakan sebuah premis mayor dalam logika silogisma deduktif.

Penelitian ini adalah salah satu upaya menggunakan sumber klasik teori hubungan internasional dalam perspektif Islam, yaitu apa yang dipraktikkan oleh Nabi Muhammad saw atau dikenal dengan istilah sunnah. Penelitian ini akan membahas tentang dimensi politik hukum internasional Perjanjian Hudaibiyah dengan memfokuskan pada masalah kepatuhan (compliance) terhadap perjanjian internasional.

Perjanjian Hudaibiyah adalah perjanjian damai yang dilakukan oleh Nabi Muhammad SAW dengan kaum Qurays Makah pada Maret 628 M (Dzulqaidah, 6 H). Perjanjian ini adalah perjanjian yang dinilai sebagai peristiwa paling penting dalam sejarah perjuangan Nabi Muhammad SAW. Sebagian besar sejarawan sirah nabawiyah menyebutkan kemenangan kaum muslimin terhadap kaum Qurays Makah tidaklah terjadi pada peristiwa Fathu Makah, tetapi justru terjadi pada peristiwa Perjanjian Hudaibiyah ketika sebagian besar sahabat menilai klausul-klausul dalam perjanjian sebagai kelemahan dan kekalahan bagi kaum muslimin (Al Ghadban,2008; Al Buthy,2010; Al Muafiri,2010; An Nadwi,2009). Para mufasir menyebutkan perjanjian ini sebagai kemenangan yang nyata dengan merujuk pada turunnya Al-quran Surat Al-fath ayat pertama: "Sesungguhnya Kami telah memberikan kepadamu kemenangan yang nyata”. (Ar Rifai,2010:Quthb,2004)

Dalam hasanah hukum internasional Islam, di samping ayat-ayat Al Quran dan Qiyas atau analogi, perkataan dan apa yang dipraktikan dalam kehidupan Nabi Muhammad SAW adalah sumber penetapan hukum (Khadduri,1956). Perjanjian Hudaibiyah dalam hal ini menjadi referensi utama para ulama dalam merumuskan prinsip dan hukum perjanjian internasional dalam Islam. Perjanjian Hudaibiyah menjadi model perjanjian internasional dalam Islam yang paling sahih. Hal ini disebabkan oleh beberapa hal: pertama perjanjian ini dilakukan langsung oleh Nabi Muhammad saw, kedua perjanjian ini menghasilkan preseden yang sangat kuat tentang perjanjian internasional sebagai salah satu instrumen memperjuangkan Islam, dan ketiga menunjukkan bahwa kemenangan bisa diperoleh justru dengan menaati perjanjian. Kemenangan ini bahkan dikabarkan langsung oleh Allah melalui diturunkannya 
ayat pertama dari surat Al-fath. Berdasarkan Perjanjian Hudaibiyah ini para ulama menetapkan kebolehan mutlak melakukan perjanjian damai antara negeri muslim dengan negeri nonmuslim.(Khadduri,2006:Bsoul,2008)

Yang menarik dari Perjanjian Hudaibiyah adalah komitmen Nabi Muhammad saw dan kaum muslimin untuk mematuhi perjanjian yang telah ditandatangani walaupun klausul-klausul dalam perjanjian dianggap sangat merugikan. Penolakan terhadap perjanjian tersebut bahkan ditunjukkan secara verbal oleh tokoh muslim sekaliber Umar bin Khattab. Akan tetapi, pada akhirnya kaum muslimin dapat menerima keputusan Nabi untuk menerima perjanjian Hudaibiyah dan mematuhi semua klausul termasuk yang dianggap sangat merugikan. Oleh karenanya, studi ini akan berfokus pada menjawab pertanyaan mengapa Nabi Muhammad dan kaum muslimin tetap komit dan patuh terhadap Perjanjian Hudaibiyah walaupun klausul-klausulnya dianggap merugikan. Dengan mengkaji permasalahan tersebut diharapkan akan mendapatkan sebuah model kepatuhan terhadap perjanjian internasional dalam perspesktif Islam.

\section{KERANGKA PEMIKIRAN}

Untuk mengulas bagaimana politik ditempatkan dalam bingkai perjanjian international (hukum internasional) dan bagaimana logika kepatuhan dibangun oleh Nabi Muhammad dalam model Perjanjian Hudaibiyah, penulis meminjam pendekatan konstruktvisme. Hal ini karena dalam ajaran Islam, posisi norma, identitas, nilai, spiritualitas memiliki kedudukan yang lebih tinggi dari dunia material. Dalam banyak pembahasan tentang amal dalam Islambaik itu amal ritual peribadatan maupun amal sosial (muammalah), selalu dimulai dari pembahasan yang panjang lebar tentang niyat. Dalam sebuah hadist yang diriwayatkan Bukhori dan Muslim dinyatakan bahwa niyat yang berada dalam struktur normatif, ideasional menjadi penentu sebuah amal yang berada dalam struktur material (Al-Bugho dan Misto,2002:11-14)

Demikian juga dalam aktivitas sosial, kenegaraan bahkan hubungan internasional, Islam sangat mementingkan norma dan nilai-nilai mengatasi pencapaian kepentingan material. Muhammad Abu Zahrah (1973) menyebutkan bahwa hubungan internasional dalam Islam terikat oleh sepuluh prinsipprinsip muamalah dalam Islam: kehormatan manusia, manusia semuanya umat yang satu, kerjasama kemanusiaan, toleransi, kemerdekaan beragama dan menentukan nasib, budi baik, keadilan, perlakuan yang sama, memenuhi janji, serta kasih sayang dan pencegahan kerusakan. Oleh karena itu pendekatan konstruktivisme dianggap lebih mampu untuk menjelaskan bagaimana struktur identitas dan norma mempengaruhi perilaku dalam kasus Perjanjian Hudaibiyah.

Dalam penelitian ini penulis menggunakan perspektif konstruktivis tentang konsep politik hukum internasional dan konsep kepatuhan (compliance) terhadap hukum internasional.

\section{Politik Hukum Internasional}

Politik hukum internasional menurut Reus-Smit (2004:14) dapat dimaknai dengan dua pembacaan. Pertama adalah bagaimana "politics informs, structures, and disciplines the law".Pandangan ini adalah pandangan yang paling lazim dianut sarjana hubungan internasional, yang mana menempatkan hukum internasional sebagai epiphenomena. Hukum internasional ditempatkan sebagai refleksi dari kekuatan politik yang mendasarinya atau sebagai solusi fungsional dari problem kerjasama antar negara. Pembacaan yang lain adalah tentang ide politik di dalam hukum. Ide bahwa hukum dapat juga ikut membentuk politik. Politik akan memiliki bentuk yang berbeda ketika berada dalam nalar dan praktik hukum.

Menurut Adler, perspektif konstruktivis tentang politik hukum internasional menentang gagasan politik adalah semata kekuasaan atau tindakan memaksimalkan keuntungan dan bahwa hukum internasional adalah epiphenomena yang hanya berupa seperangkat aturan fungsional. (dalam Smit,2004:21) Ada tiga proposi yang diajukan oleh konstrutivisme tentang sifat sosial dari hubungan internasional. Pertama dalam batas tertentu struktur normatif dan 
ideasional sama pentingnya dengan struktur material dalam membentuk perilaku negara dan aktor lainnya dalam hubungan internasional. Tidak hanya pengetahuan bersama yang melekat pada struktur yang menentukan bagaimana aktor merespon lingkungan material mereka, tetapi juga keyakinan intersubjektif ikut membentuk identitas dan pada gilirannya menentukan kepentingan mereka. Kedua, konstruktivis berpendapat bahwa jika kita ingin memahami perilaku negara dan aktor lainnya kita harus bisa mengetahui bagaimana identitas sosial mereka membentuk kepentingan dan tindakan mereka. Ketiga, walaupun menekankan kekuatan konstitutif dari struktur norma dan ideasional, mereka menekankan diperlukannya praktik yang terus berkelanjutan dari knowledgable social agent agar struktur norma atau ide tersebut eksis.

Berbeda dari realis dan rationalis yang menempatkan politik sebagai fungsi kepentingan, construtivis menempatkan politik dalam dimensi nalar dan aksi (political reason and political action). Dalam hal ini tindakan politik ditentukan oleh nalar politiknya (political reason). Nalar politik dibentuk secara konstitutif oleh empat elemen: idiographic, purposive, ethical dan intsrumental. Nalar ideografis adalah ketika berusaha menjawab pertanyaan Who are we? Sementara nalar purposif adalah menjawab pertanyaan What do I/ we want? Nalar etis adalah menjawab pertanyaan how we should act? Dan nalar instrumental menjawab pertanyaan how do we get what we want?

\section{Kepatuhan (compliance)}

Salah satu masalah utama dalam hukum internasional adalah soal kepatuhan (compliance). Keberadaan hukum internasional bahkan sering kali diukur dari ada atau tidaknya kepatuhan terhadapnya. Oleh karenanya para sarjana hubungan internasional dan hukum internasional telah banyak mengkaji tentang apakah hukum internasional dipatuhi atau mengapa negara patuh terhadap perjanjian internasional.(Guzman, 2002:1826)

Menurut Kingsbury (1999:346) konsep kepatuhan (compliance) walaupun banyak digunakan dalam berbagai studi hubungan internasional maupun hukum internasional bukanlah konsep yang memiliki makna tunggal dan berdiri sendiri. Pengertian kepatuhan adalah turunan dari teori tentang makna dan kegunaan hukum internasional itu sendiri. Oleh karenanya berbeda teori akan menghasilkan pengertian yang berbeda tentang kepatuhan.

Dalam pandangan konstruktivis hukum internasional tidaklah dipandang sebagai bersifat regulatif, tetapi bersifat konstitutif. Kepatuhan terhadap hukum internasional dimulai sejauh internalisasi norma oleh masyarakat internasional sehingga menjadi habit untuk patuh, kepatuhan juga muncul karena aktor menerimanya sebagai sesuatu aturan yang sahih, sesuatu yang benar untuk dilakukan (identitive motive) atau sesuatu yang dibenarkan oleh para pemikir konstruktivisme.

Penelitian ini akan dilakukan dengan metode kualitatif. Metode kualitatif digunakan karena memungkinan untuk mendapatkan pemahaman yang lebih holistik dan mendalam tentang sebuah fenomena sosial (Silverman,2005:10) Karena fenomena soal tidak bisa direduksi menjadi variabel-variabel dalam cara yang sama dengan fenomena fisik, maka ia harus dipahami dari perspektif "the insider" yang melibatkan subjektivitas peneliti. Metode kualitatif sesuai digunakan untuk penelitian yang menjawab pertanyaan yang dimulai dengan mengapa? bagaimana? Dengan cara apa (in what way)?(Trent Focus, 1998:3-4).

Data dalam penelitian ini dikumpulkan melalui studi pustaka. Data-data kepustakaan lain baik yang berupa buku, jurnal, artikel,berita di media cetak dan dokumen-dokumen online di internet akan digunakan untuk analisis dan pemaknaan fenomena di seputar Perjanjian Hudaibiyah.

\section{HASIL DAN PEMBAHASAN}

ANALISIS FAKTOR-FAKTOR YANG MENYEBABKAN KEPATUHAN NABI MUHAMMAD SAW DAN UMMAT ISLAM TERHADAP PERJANJIAN HUDAIBIYAH

Berdasarkan kerangka konseptualdi atas, kepatuhan ummat Islam terhadap Perjanjian Hudaibiyah dapat dijelaskan dengan mengidentifikasi struktur ideasional atau nalar politiknya, yaitu nalar idiografis (idiographic), 
nalar purposif (purposive), nalar etis (ethical) dan nalar instrumental (instrumental). Interseksi dari empat nalar politik itulah yang pada gilirannya menentukan tindakan politik aktor.

\section{Nalar Idiografis}

Nalar ideografis mengambil tempat ketika aktor dikonfrontasi dengan pertanyaan siapa kita (who we are?). Dengan demikian nalar ideografis merupakan aspek yang bersifat identitif. Konstruktivisme memandang konstruksi sosial identitas dan pemaknaan antaraktor dalam sistem internasional memainkan peranan penting dalam hubungan internasional. Alexander Wendt (dalam Kingsbury, 1998) mengakui bahwa negara adalah utama dalam hubungan internasional, tetapi berpendapat bahwa stuktur kunci yang menentukan dalam system internasional bukanlah kepentingan material melainkan hubungan intersubjektif yang pada gilirannya membentuk identitas sosial.

Menurutnya ada dua jenis identitas yang dimiliki negara, yaitu identitas korporat (corporate identity) dan identitas sosial (social identity). Identitas korporat terdiri dari unsur-unsur intrinsik,self organizing qualities yang membentuk individualitas actor. Sementara identitas sosial adalah serangkaian pemaknaan yang diberikan oleh aktor itu sendiri sambil pada saat yang sama mengambil perspektif aktor lain dalam interaksinya dengan sistem internasional. Seperti apa aktor ingin dimaknai dalam perspektif aktor lain itulah identitas sosial.

Identitas ummat Islam yang diproyeksikan kepada aktor lain dalam interaksi sosial dapat kita simak dalam ungkapan Ja'far bin Abi Thalib di hadapan Raja Najasy. Ja'far bin Abi Thalib adalah salah seorang sahabat Nabi Muhammad saw yang diutus untuk memimpin rombongan kaum muslim untuk mendapatkan suaka dari Raja Najasy di Etiopia akibat perlakuan kejam dan permusuhan dari kaum pagan di Makah. Di hadapan sang Raja yang menganut agama Nasrani ini Ja'far menyatakan identitas umat Islam sebagai berikut.

"Wahai Tuan Raja, dulu kami adalah pemeluk agama jahiliyah. Kami menyembah berhala-berhala, memakan bangkai, berbuat mesum, memutuskan tali persaudaraan, menyakiti tetangga dan yang kuat di antara kami memakan yang lemah. Begitulah gambaran kami dahulu hingga Allah mengutus seorang rasul dari kalangan kami sendiri, yang kami ketahui nasab, kejujuran, amanah, dan kesucian dirinya. Beliau menyeru kami kepada Allah untuk mengesakan dan menyembah-Nya serta meninggalkan penyembahan kami dan bapak-bapak kami terhadap batu dan patung. Beliau juga memerintahkan kami untuk berkata jujur, melaksanakan amanat, menjalin hubungan kekerabatan, berbuat baik kepada tetangga, menghormati hal-hal yang disucikan dan darah. Beliau melarang kami berbuat mesum, berkata palsu, mengambil harta anak yatim dan menuduh wanitawanita yang suci. Beliau menyuruh kami untuk menyembah Allah semata, tidak menyekutukannya dengan sesuatu pun dengan-Nya, memerintahkan kami mengerjakan shalat, mengeluarkan zakat dan berpuasa (dia menyebutkan ajaran-ajaran Islam yang lain). Lalu kami membenarkan, beriman dan mengikuti beliau atas apa pun dari agama Allah. Lalu kami menyembah Allah semata, tidak menyekutukan sesuatu dengan-Nya, kami apa pun yang diharamkan atas kami, menghalalkan apa pun yang dihalalkan bagi kami. Lalu kaum kami memusuhi kami, menyiksa kami dan menimbulkan cobaan bagi agama kami dengan tujuan untuk mengembalikan kami kepada penyembahan kepada patung, tanpa diperbolehkan menyembah Allah, agar kami menghalalkan berbagai macam keburukan seperti dahulu..." (al Mubarakfury,1997:130-131)

Dari pernyataan Ja'far di atas dapat disimpulkan bahwa ummat Islam dalam interaksi sosialnya memproyeksikan dirinya dengan beberapa atribut identitas: kaum yang mengimani Allah sebagai satusatunya Tuhan yang disembah dan dipatuhi perintah dan larangannya, kaum mengimani Muhammad sebagai nabi utusan Allah dan mematuhinya, kaum yang menghormati sesama manusia dan berinteraksi sosial dengan akhlak mulia seperti berkata jujur, melaksanakan amanat, menjalin hubungan kekerabatan, berbuat baik kepada tetangga, menghormati hal-hal yang disucikan dan darah, tidak 
berkata palsu,tidak mengambil harta anak yatim dan menuduh wanita-wanita yang suci.

Ummat Islam memproyeksikan dirinya sebagai ummat yang mulia karena menganut agama yang mereka yakini kebenaran dan kemuliaannya. Mereka menganggap diri mereka sebagai ummat yang beradab. Mereka merasa telah keluar dari belenggu kejahiliyahan ajaran nenek moyang mereka. Mereka kini adalah ummat yang mulia. Oleh karenanya ummat Islam rela menderita dan berjuang untuk mempertahankan kemuliaan agama mereka, membela Nabi Muhammad sebagai pemimpin mereka, dan menyebarkan agama mereka.

Identitas ummat islam sebagai ummat yang mulia karena memeluk agama yang mereka yakini kebenarannya tergambar dari pernyataan Ummar bin Khattab ketika Nabi Muhammad menyepakati Perjanjian Hudaibiyah yang dianggap merugikan dan menghinakan ummat Islam. Ummar menggugat Nabi Muhammad:

"Umar Ibnul Khattab ra. Berkata kepada Rasulullah saw.," Ya Rasulullah, bukankan Anda utusan Allah?" "Benar," jawab Rasul.

"Bukankah kita berada pada kebenaran?" tanya Umar pula.

"Benar," jawab beliau.

"Bukankan musuh kita itu berada pada kebatilan?

"Ya," jawab Rasul.

"Tapi, mengapakah kita memberi kehinaan dalam agama kita?" tanya Umar.

Rasulullah menegaskan,"Sesungguhnya aku adalah Rasul

Allah. Aku takkan mendurhakai-Nya. Dia pun takkan menyia-nyiakan aku." (Al Ghadban,2008:49)

Ummat Islam sebagai ummat yang mulia dan beradab merasa tidak layak untuk dihina dan ditindas oleh ummat yang lain. Apalagi oleh kaum yang menurut mereka berada di dalam kebodohan agama pagan dan kebiasaan nenek moyang yang tidak beradab sebagaimana kaum pagan Makah. Oleh karenanya kaum muslim merasa berhak untuk diakui sebagaimana kabilah-kabilah lain yang ada di kawasan Arab pada saat itu. Kaum muslimin merasa harus diperlakukan sama di hadapan hukum kebiasaan yang berlaku di masyarakat Arab pada saat itu, termasuk di dalamnya adalah hak untuk melakukan ziarah ke Ka'bah yang berada di Makah.

Pada masa itu hampir semua kabilah di jazirah Arab dengan berbagi agama dan keyakinan menganggap Ka'bah adalah tempat yang disucikan. Mereka dari berbagai kabilah dan agama memiliki tradisi ritual beribadah dengan thawaf mengelilingi ka'bah dengan tata cara ibadah masing-masing.(Al Mubarakfury,1997:49-58). Kaum Quraisy Makah memiliki posisi terhormat karena dianggap sebagai penjaga ka'bah. Makah menerima berbagai keuntungan ekonomi karena banyaknya para peziarah yang datang ke Ka'bah terutama pada bulan-bulan yang disucikan. Bulan di mana diharamkan untuk berperang dan menumpahkan darah. Pada peristiwa Hudaibiyah kaum muslimin berniat berziarah ke Makah untuk melaksankan ibadah umrah walaupun mereka dalam situasi perang dengan kaum Quraisy. Sebagai ummat yang beradab mereka pergi ke Makah tanpa persenjataan karena pada bulan itu diharamkan berperang dan tujuan mereka adalah untuk beribadah.

\section{Nalar Purposif}

Nalar purposif terjadi ketika ada pertanyaan apa yang kita inginkan (what do we want)? Ungkapan yang menunjukkan nalar purposif dari ummat Islam adalah ungkapan Rib'i bin Amir kepada Rustum panglima perang Persia "Sesungguhnya Allah mengutus kami untuk mengeluarkan manusia dari menyembah sesama kepada menyembah Allah saja, dari kesempitan dunia kepada kelapangannya, dari kedzaliman berbagai agama kepada keadilan Islam" (Qardhawy,1997:15)

Ungkapan di atas secara jelas menyatakan bahwa nalar purposif ummat islam adalah menyebarkan/ mendakwahkan Islam kepada seluruh manusia. Dalam hal telah terbentuk negara Islam, misi ini kemudian diemban oleh negara. Misi ini selaras dengan diutusnya Nabi Muhammad sebagai nabi terakhir. Berbeda dengan nabi sebelumnya yang ajarannya hanya berlaku pada ummat tertentu, ajaran yang dibawa Nabi Muhammad berlaku untuk semua manusia sepanjang zaman. Bahkan Nabi Muhammad diutus sebagai kasih 
sayang Allah bagi seluruh alam semesta.Hal tersebut termaktub dalam Al Quran:

"Dan Kami tidak mengutus kamu, melainkan kepada umat manusia seluruhnya sebagai pembawa berita gembira dan sebagai pemberi peringatan, tetapi kebanyakan manusia tiada mengetahui. (QS. Saba`:28) Dan tiadalah Kami mengutus kamu, melainkan untuk (menjadi) rahmat bagi semesta alam". (QS. AlAnbiyaa':107)

Abou-Kazleh menyatakan bahwa peran negara dalam yurisprudendi klasik Islam adalah secara internal adalah mendakwahkan Islam, melindungi kehidupan, kepemilikan dankeimanan ummat Islam dan secara eksternal mengajak manusia kepada Islam karena Islam adalah agama universal. Sebagaimana dikutip oleh Tadjbakhsh (2010:190)

Classical Islamic jurisprudence clarifies the role of the Islamic state in the binary division of international relations, whether war or peace is the organizing principle between the two, on the imperative of abiding by the rule of Islamic law: internally, preaching Islam and protecting the lives, property and faith of believers within, and externally, inviting people to Islam because Islam is a universal religion. (Abo-Kazleh 2006: 43)

Dalam melaksanakan dakwah harus dilakukan dengan cara damai penuh kebijakan, pengajaran yang dan argumentasi yang baik (Al-quran, Surat Annahl:125). Dalam berdakwah juga dilarang menggunakan cara-cara paksaan dan intimidasi karena Islam menghormati kebebasan beragama. Dalam Al Quran dinyatakan "Tidak ada paksaan untuk (memasuki) agama (Islam); sesungguhnya telah jelas jalan yang benar daripada jalan yang sesat." (Surat alBaqoroh: 256). Ayat ini menghajatkan dakwah harus dilakukan dalam situasi yang damai dan adanya jaminan kebebasan beragama. Hanya dalam keadaan damai dan bebas proses mencari kejelasan "jalan yang benar daripada jalan yang sesat" dapat dilakukan dengan penuh keleluasaan.

Berdasarkah hal di atas keadaan yang diinginkan oleh Islam adalah keadaan damai. Asas hubungan antar negara dalam Islam adalah damai (Abu
Zahrah,1973). Oleh karena itu Nabi Muhammad, dalam peristiwa Perjanjian Hudaibiyah, sejak awal sudah menginginkan terjadinya perdamaian dengan Quraiys (al-Ghadban,2008:28-29). Hal ini dilakukan dengan secara sengaja tidak membawa persenjataan di dalam misi ibadah umrah tersebut. Yang diharapkan dengan diperbolehkannya ummat Islam memasuki Makah dengan damai, secara simbolis telah terjadi pengakuan terhadap eksistensi ummat Islam di Madinah sebagai entitas politik yang setara dengan kabilah-kabilah lain. Namun, harapan tersebut tidak terjadi karena kaum Quraisy berkeras menolak masuknya kaum muslimin ke Makah, bahkan melakukan provokasi agar terjadi bentrokan. Sampai akhirnya terjadilah perjanjian damai antar kedua belah pihak walau hasilnya hampir semua klausul yang disepakati dianggap merugikan ummat Islam.

\section{Nalar Etis}

Nalar etis terjadi ketika ditanyakan bagaimana kita harus bertindak. Nalar ini menempatkan nalar purposif dan nalar instrumental dalam timbangan norma yang secara interal diyakini dan norma sosial atau customary law yang berlaku saat itu. Secara sosial, pada masa itu telah berlaku hukum adat yang menyatakan bahwa perjanjian haruslah dipatuhi. Pihak yang tidak mematuhi perjanjian dianggap pihak yang tidak terhormat yang karenanya akan mendapatkan sanksi sosial. Secara internal ummat Islam norma mematuhi perjanjian adalah norma yang memiliki landasan yang sangat kuat. Keharusan mematuhi perjanjian adalah ketentuan yang secara eksplisit dinyatakan dalam Al Quran dalam banyak ayat:

"Wahai orang-orang yang beriman, penuhilah janjijanji." (Al Maidah: 1)

"Dan tepatilah perjanjian dengan Allah apabila kamu berjanji dan janganlah kamu membatalkan sumpahsumpah itu sesudah meneguhkannya...." (An-Nahl: 91) "Kecuali orang-orang musyrikin yang kamu telah mengadakan perjanjian (dengan mereka) dan mereka tidak mengurangi sesuatu pun (dari isi perjanjian)mu dan tidak (pula) mereka membantu seseorang yang memusuhi kamu, maka terhadap mereka penuhilah janjinya sampai batas waktunya. Sesungguhnya Allah menyukai orang- 
orang yang bertakwa." (At-Taubah: 4)

Dan janganlah kamu jadikan sumpah-sumpahmu sebagai alat penipu di antaramu..." (An Nahl: 94-95)

Dari ayat-ayat di atas jelas bahwa memenuhi janji bagi ummat islam bukan hanya kewajiban yang timbul karena kesepakatan para pihak, melainkan juga merupakan kewajiban yang bersifat spiritual. Ketidakpatuhan terhadap perjanjian bukan hanya memungkinkan mendapatkan sanksi sosial, tetapi juga akan mendapatkan sanksi di akhirat (dosa). Dalam hal ini norma memenuhi perjanjian secara kuat terinternalisasi dalam ummat Islam.

\section{Nalar Instrumental}

Nalar instrumental adalah pertimbangan yang mempertentangkan dua pertanyaan. Yang pertama bersifat strategis instrumental, yaitu pertanyaan bagaimana saya/kita mendatkan apa yang kita inginkan? (how do I/we get what I/we want?). Yang kedua bersifat resource-instrumental, yaitu pertanyaan apa yang saya/kita butuhkan untuk mendapatkan apa yang saya/ kita inginkan? (what do I/we need to get what I/we want?).

Pertimbangan instrumental ini mempertemukan antara alternatif strategi yang tersedia dalam sebuah upaya mencapai tujuan dengan ketersediaan sumberdaya yang diperlukan untuk melaksanakan strategi tertentu. Pertimbangan memilih tindakan atau langkah strategis tertentu untuk mencapai tujuan pada akhirnya dibatasi oleh ketersediaan sumberdaya yang diperlukan untuk melaksanakan strategi tertentu dengan baik.

Dalam kasus pelaksanaan Perjanjian Hudaibiyah, ketika dalam pelaksanaan perjanjian ternyata dirasa merugikan atau memberatkan kepentingan kaum muslimin, terdapat dua pilihan strategi: mematuhi perjanjian atau mengabaikan perjanjian. Ketika pilihan strateginya adalah mematuhi perjanjian, maka yang diperlukan adalah soliditas barisan pengikut untuk mampu menahan diri dan meredam emosi. Sementara ketika pilihannya mengabaikan perundingan maka sumberdaya yang diperlukan adalah kekuatan militer dan kesiapan moral untuk berperang menghadapi kaum Quraisy Makah dan sekutunya.

Apabila melihat aspek tujuan dari tercapainya perjanjian damai, yaitu terciptanya situasi yang kondusif bagi pelaksanaan misi dakwah, jika opsi yang dipilih adalah mengabaikan perjanjian dengan resiko perang, sumber daya yang diperlukan adalah kekuatan militer yang dipastikan mampu mengalahkan pasukan Quraisy. Hanya dengan mengalahkan Quraisylah tujuan menciptakan suasana damai dan aman dalam menjalankan misi dakwah akan tercapai. Sumber daya yang lain adalah kemampuan mempertahankan atau membentuk citra positif di hadapan kabilah atau suku lain di Jazirah Arab. Melanggar perjanjian adalah sesuatu yang dipandang tindakan yang tidak terpuji. Tindakan tersebut juga akan bertentangan dengan identitas kaum muslimin sebagai kaum yang menepati janji.

Pada saat terjadinya perjanjian Hudaibiyah, reputasi kekuatan muslim sebenarnya cukup baik. Mereka berhasil bertahan dari kepungan 10.000 pasukan Quraisy dan sekutunya dalam perang Ahzab. Pasca perang Ahzab tidak ada kabilah Arab yang menyatakan bergabung dengan Quraisy karena mereka tidak lagi yakin akan kemampuan militer Quraisy mengalahkan kaum muslimin di Madinah. Namun pada saat itu, menghadapi ancaman Yahudi Khaibar yang berada di Utara Madinah. Jika kaum muslim melakukan ekspedisi ke Khaibar maka Madinah kosong dan ada kemungkinan akan dimanfaatkan oleh Quraisy, demikian juga sebaliknya. Kekuatan Islam tidak cukup untuk menghadapi kedua ancaman tersebut pada waktu yang bersamaan. Itulah mengapa Nabi Muhammad menginginkan perdamaian dengan Quraisy sehingga bisa berkonsentrasi untuk menghadapi Yahudi di Khaibar (Hamidullah,1987)

Berdasarkan pertimbangan itu maka jawaban dari pertanyaan bagaimana kita mencapai apa yang kita inginkan dijawab dengan mematuhi perjanjian. Sementara pertanyaan "apa yang kita perlukan untuk mendapatkan yang kita inginkan?" dijawab dengan komitmen untuk menahan diri dari emosi dan tindakan yang melanggar perjanjian dan disiplin mematuhi perjanjian.

\section{KESIMPULAN}

Penelitian ini berkesimpulan Nabi Muhammad saw 
tetap mematuhi Hudaibiyah karena nalar politik idiographic, purposive, ethical dan intsrumental. Secara ideografis didasari oleh identitas sebagai mukmin yang harus mentaati Allah dan Rasulnya, kaum yang mulia,sebagai kaum yang memegang janji. Secara purposif yang diinginkan oleh kaum muslim adalah mendakwahkan agama tauhid kepada seluruh manusia, oleh karena itu kebebasan beragama harus terwujud. Secara etis, pertanyaan how should we act dijawab dengan harus sesuai dengan aturan Islam dan normanorma bersama (customary law) yang berlaku dalam hal ini Islam memerintahkan untuk memenuhi perjanjian dan melarang menggunakan perjanjian sebagai alat menipu. Di sisi lain keharusan menaati perjanjian merupakan norma hubungan antarbangsa yang berlaku. Secara instrumental yang diperlukan untuk mencapai tujuan adalah ditaatinya perjanjian damai. Dalam hal ini dapat diambil benang merah bahwa nalar ideografis yaitu pendefinisian identitas menentukan pendefinisian kepentingan atau nalar purposif. Sementara nalar etis membatasi pilihan strategi dalam upaya meraih kepentingan (nalar instrumental). Dalam nalar intsrumental selain dibatasi oleh nalar etis, pilihan strategi juga ditentukan oleh ketersediaan sumberdaya yang diperlukan untuk menjalankan strategi tertentu dan hambatan eksternal yang ada.

\section{REFERENSI}

Abu Sulayman, Abdul Hamid A.1987. The Islamic Theory of International Relations: New Directions for Islamic Methodology and Thought. Herndon, WV:International Institute of Islamic Thought Abu Zahrah, Muhammad.1973. Hubungan-Hubungan Internasional dalam Islam. Terj.Jakarta: Penerbit Bulan Bintang

Al Buqha, Musthafa dan Misto,Muhyidin.2002. Pokok-Pokok Ajaran Islam: Syarah Arbain An Nawawiyah. Terj. Jakarta: Robbani Press.

Al Ghadban, Munir Muhammad. 2008. Manhaj Haraki: Strategi Pergerakan dan Perjuangan Politik dalam Sirah Nabi Saw. Terj. Jakarta: Robbani Press

Al Mubarakfury, Syafiyyurrahman. 1997. Sirah Nabawiyah. Terj. Jakarta:Pustaka Al Kautsar

Al-Buthy, Said Ramadhan. 2010. Fikih Sirah. Terj. Jakarta:Hikmah Al-Muafiri, Abu Muhammad Abdul Malik bin Hisyam. 2010. Sirah Nabawiyah Ibnu Hisyam. Jilid 2. Terj. Bekasi: Darul Falah.

An-Nadwi, Abul Hasan Ali Al Hasani. 2009. Sirah Nabawiyah: Sejarah Lengkap Nabi Muhammad SAW. Terj. Yogyakarta: Mardhiyah Press. Ar-Rifai, Muhammad Nasib. 2000. Kemudahan dari Allah: Ringkasan
Tafsir Ibnu Katsir. Jilid 4. Terj. Jakarta: Gema Insani Press.

Ashri, Muhammad dan Rapung Samudin.2013. Hukum Internasional dan Hukum Islam tentang Sengketa dan Perdamaian. Jakarta: PT Gramedia Pustaka Utama

Bao,Wang Yong (Ahmed Musa).2009. Diplomacy: Theory and Practice in Islam. Kuala Lumpur: International Islamic University Malaysia.

Bsoul, Labeeb Ahmed.2008.International Treaties (Mu'ahadaat) in Islam: Theory and Practice in the Light of Islamic International Law (siyar) according to Ortodox Schools. Plymouth: University Press of America

Chalil, Moenawar. 2001. Kelengkapan Tarikh Nabi Muhammad SAW. Jilid 4. Terj. Jakarta: Gema Insani Press.

Guzman,Andrew T. 2002. "A Compliance Based Theory of International Law".California Law Review. Vol 90. Tersedia dihttp:// works.bepress.com/andrew_guzman/8. Diakses 15 Juli 2011

Hamidullah, Muhammad. 1987. Muslim Conduct of State. Lahore: SH. Muhammad Ashraf

Hilal, lyad.2002. Perjanjian-Perjanjian Internasional dalam Pandangan Islam. Bogor: Pustaka Thariqul Izzah.

Iqbal, Afzal.2000. Diplomasi Islam. Jakarta: Pustaka Al-Kautsar

Khadduri,Majid.1956. "Islam and the Modern Law of Nations". The American Journal of International Law. Vol 50.No 2. April. Diakses melalui JStor di http://www.jstor.org/stable/2194954

Khadduri,Majid.2006. War and Peace in the Law of Islam. New Jersey: The Lawbook Exchage,LTD

Kingsbury,Benedict.1998." The Concept of Compliance as A function of Competing Conceptions of International Law". Michigan Journal of InternationalLaw. Vol19. No 2. Winter. Tersedia di http:// www.iilj.org/aboutus/documents/TheConceptofCompliance.pdf diakses 17 Juli 2011

Lele, Gabriel dkk. 2010. Panduan Penulisan Akademik. Yogyakarta: Fisipol UGM

Pipes, Daniel.1999." Al Hudaibiya and Lesson from Prophet Muhammads diplomacy ".Middle East Quarterly. September 1999.http://www.danielpipes.org/316/al-hudaybiya-and-lessonsfrom-the-prophet-muhammads. diakses tanggal 18 Juli 2011

Qureshi,Muhammad Siddique.1991. Foreign Policy of Hadrat Muhammad (saw). New Delhi: Kitab Bavhan

Quthb, Sayyid. 2004. Tafsir Fi Zhilalil Quran: Di Bawah Naungan Al Quran. Jilid 20. Terj. Jakarta: Gema Insani Press.

Rochester, J.Martin. 2006. Between Peril and Promise: The Politics of International Law. Whasington D.C.: CQ Press.

Silverman, David.2005. Doing Qualitative Research: A Practical Handbook.2ed. London: Sage Publications.

Smit, Christian Reus (ed). 2004. The Politics of International Law. Cambrigde: Cambridge University Press

Smith, Perry. 2006. "Of War and Peace: The Hudaibiya Model of Islamic Diplomacy". Florida Journal of International Law.Vol 18.p.136-167

Tadjbakhsh, Shahrbanou.2010. "International Relations Theory And The Islamic Worldview". dalam Acharya, Amitav and Barry Buzan. 2010. Non-Western International Relations Theory Perspectives on and beyond Asia. New York: Routledge

Vienna Convention on the law of treaties (with annex). Tersedia di https://treaties.un.org/doc/Publication/UNTS/Nolume\%201155/ volume-1155-I-18232-English.pdf diakses 14 Juli 2014 